\title{
Lysosomotropic compounds and spermine enzymatic oxidation products in cancer therapy (Review)
}

\author{
ENZO AGOSTINELLI and NIKOLAUS SEILER
}

\author{
${ }^{1}$ Department of Biochemical Sciences 'A. Rossi Fanelli', University of Rome 'La Sapienza' and CNR, Institute of \\ Molecular Biology and Pathology, Piazzale A. Moro 5, 00185 Rome, Italy; ${ }^{2}$ Laboratory of Nutritional Cancer Prevention, \\ ULP-EA3430, Institut de Recherche contre les Cancers de l'Appareil Digestif (IRCAD), Strasbourg, France
}

Received March 12, 2007; Accepted April 27, 2007

\begin{abstract}
Apoptotic pathways represent the mechanisms of programmed cell death that counteract initiation and progression of cancer. New therapeutic targets are currently being explored on the basis of our detailed knowledge of the mechanisms and factors involved in apoptosis. In recent years, numerous proteins have been identified, which act as tumour suppressors or as oncoproteins in caspase-independent programmed cell death mechanisms, in which lysosomes are implicated for their lysosomal functions in cancer, mainly attributed to lysosomal proteinases, particularly the cathepsins. If cathepsins are released from the lysosomal lumen into the cytoplasm they initiate a number of processes that may cause either apoptotic or non-apoptotic (necrotic) cell death. The release of cathepsin D into the cytoplasm by vacuolar-type ATPase (V-ATPase) inhibitors produces the characteristic signs of apoptotic cell death, including caspase-3 activation and DNA laddering. For the destabilisation of the lysosomal membrane, two methods are available having therapeutic potential: the formation of reactive oxygen species (ROS) by irradiation or by enzymatic reactions and the lysosomal membrane permeabilisation by lysosomotropic compounds. Findings also suggest that the deregulation of polyamine metabolism or cytotoxic metabolites generated from the oxidative deamination of spermine by amine oxidases in
\end{abstract}

Correspondence to: Professor Enzo Agostinelli, Department of Biochemical Sciences 'A. Rossi Fanelli', University of Rome 'La Sapienza', Piazzale A. Moro 5, 00185 Rome, Italy

E-mail: enzo.agostinelli@uniromal.it

Abbreviations: ADR, adriamicin resistant; AO, amine oxidase; BHK, baby hamster kidney; BSAO, bovine serum amine oxidase; DX, doxorubicin; FAD, flavin-adenin-dinucleotide; HSP, heat shock protein; IU, international units; MDL 72527, $\mathrm{N}^{1}, \mathrm{~N}^{4}$-bis(2,3butadienyl)-1,4-butanediamine dihydrochloride; MDR, multidrug resistance; PAO, polyamine oxidase; PEG, poly-ethylene glycol; ROS, reactive oxygen species; TEM, transmission electron microscopy; V-ATPases, vacuolar-type ATPases; WT, wild-type

Key words: polyamines, multidrug resistance, MDL 72527 , lysosomes, lysosomotropic compounds, colon adenocarcinoma association with lysosomotropic compounds may induce apoptosis. Cross-resistance of cells to cytotoxic actions of a wide variety of natural and synthetic anticancer drugs is the well-known phenomenon called multidrug resistance (MDR), due to glycoprotein P that functions as an ATP-dependent pump. The sensitisation of tumour cells to anticancer drugs by lysosomotropic compounds, and particularly the sensitisation of MDR-resistant cells recommend scrutinizing the potential of lysosomotropic drugs in cancer therapy.

\section{Contents}

1. Introduction

2. Functions of lysosomes

3. Permeabilization of lysosomal membranes and apoptosis

4. Lysosomotropy is not sufficient to kill cells

5. Inhibitors of vacuolar ATPases mimic effects of lysosomotropic compounds

6. Cytotoxic lysosomotropic compounds

7. Sensitisation of cancer cells to anticancer treatment by lysosomotropic compounds

8. Hydrogen peroxide and spermine oxidation products induce damage of lysosomal membrane and multidrug-resistant cells

9. Concluding remarks

\section{Introduction}

Apoptotic pathways are the best studied programs that counteract initiation and progression of cancer (1). Consequently, new therapeutic targets are currently being explored on the basis of our detailed knowledge of the mechanisms and factors involved in apoptosis (2). For many years, interest was mainly focused on mitochondrial and death receptormediated apoptosis signalling pathways, which converge at the level of caspase- 3 activation. In recent years, more proteins have been identified, which act as tumour suppressors or as oncoproteins in caspase-independent programmed cell death mechanisms, in which lysosomes are implicated (3-5). Numerous reviews document the revival of interest in lysosomal functions, particularly in cancer (6-11). It is now well established that lysosomal proteinases, particularly the 
cathepsins, contribute in several ways to apoptotic and nonapoptotic cell death (12). Cathepsins have multiple functions. Cysteine cathepsins $\mathrm{B}$ and $\mathrm{L}$ and the aspartate cathepsin D are implicated in malignant transformation and in cancer progression (13-15).

Apoptosis is morphologically characterised by rounding up of the cell, retraction of pseudopodia, reduction of cellular volume, condensation of the chromatin, fragmentation of the nucleus, plasma membrane blebbing, but little modification of the cytoplasmic organelles (5) and maintenance of an intact plasma membrane. In contrast, autophagic cell death occurs without chromatin condensation and is accompanied by massive vacuolisation of the cytoplasm (10). The vacuoles may contain degenerating cytoplasmic organelles. According to Bursch (16), autophagic-programmed cell death and apoptosis, although morphologically different, should not be considered as mutually exclusive phenomena. Both reflect cell responses to physiological and pathological changes of the environmental conditions. In addition to their function in the cleavage of cytoplasmic constituents within the lysosomal lumen, diverse signals are mediated by lysosomal proteinases to caspases, and thus to apoptosis. For example, radiation-induced cell death involves the formation of reactive oxygen species (ROS) that cause lysosomal destabilisation and induce caspase activation (17). Radiation-induced cell death belongs, therefore, to the category of lysosome-dependent apoptosis. In addition to radiation, a variety of cytotoxic drugs are capable of inducing apoptosis by accumulating within the lysosomes, and releasing lysosomal proteases, due to the impairment of the lysosomal membrane.

Several findings suggest that the deregulation of metabolism of polyamines (putrescine, spermidine, spermine and related compounds) may induce apoptosis (18). Apart from being of vital importance for the propagation and viability of most cells the natural polyamines spermidine and spermine are also the source of cytotoxic metabolites. The oxidative deamination of spermine by bovine serum amine oxidase (BSAO: EC 1.4.3.6) generates hydrogen peroxide, aldehydes and ammonia. Hydrogen peroxide and aldehydes induce apoptotic and nonapoptotic cell death. We demonstrated that the induction of cell death was potentiated by the combined treatments of $\mathrm{BSAO} /$ spermine with MDL $72527\left[\mathrm{~N}^{1}, \mathrm{~N}^{4}\right.$-bis(2,3-butadienyl)-1,4butanediamine dihydrochloride], an inactivator of flavinadenin-dinucleotide (FAD)-dependent amine oxidase (AO), with lysosomotropic properties (19). Other lysosomotropic compounds that sensitize tumour cells to toxic spermine metabolites, such as chloroquine, are being investigated. A systematic exploration of the potential of this category of compounds in cancer therapy has not been published. It seems therefore of interest to review the sporadic observations and to investigate the chances of lysosomotropic drugs in cancer therapy.

\section{Functions of lysosomes}

The digestion of redundant cellular material has long been considered to be the exclusive function of lysosomes $(20,21)$. However, more recent work has demonstrated that the processes that involve lysosomes are not unspecific catabolic mechanisms, but targeted functions $(8,22,9)$.
The release of lysosomal enzymes is a physiological process. The mechanism of secretion of lysosomal enzymes, their fate and the mechanisms by which extracellular inhibitors of the lysosomal enzymes may prevent tissue damage have been reviewed by Davies and Allison (23).

Two pathways are mainly involved in the degradation of cellular material: the ubiquitin-proteasome pathway (24) and autophagy (22). The latter term designates any intracellular process that results in the complete degradation of cytoplasmic components to amino acids and nucleotides inside the lysosomes. Based on the way substrates reach the lysosomal lumen, one distinguishes between three major forms of autophagy (25). In macroautophagy the substrates are first sequestered by a membrane of non-lysosomal origin ('autophagosome'). Fusion of the autophagosomes with lysosomes exposes the contents of the autophagosome to an array of proteolytic enzymes $(26,27)$. In microautophagy the lysosomal membrane itself engulfs the cytosolic substrates. In chaperone-mediated autophagy, soluble proteins bind to a cytosolic chaperone. Selectivity depends on the recognition of an amino acid sequence of the substrate protein by the chaperone. The substrate-chaperone complex binds to a receptor of the lysosomal membrane that mediates its translocation into the lysosomal lumen (28). While only some forms of macroautophagy and microautophagy are selective, chaperonemediated autophagy is always selective.

Most cells have the ability of autophagy, though to different degrees. The basal autophagic activity reflects a role in the control of the turnover of proteins but, in contrast with the multi-enzyme proteasome system, autophagy is suited to remove not only proteins, but also functionally redundant cell organelles.

Concerning cancer, the role of autophagy is Ianus faced. In theory, both activation and inactivation of autophagy could support tumour growth (9). In later stages of tumour growth, the cells of inner layers (in contrast with the wellvascularised cells of the outer layers) have insufficient access to oxygen and nutrients. In this situation, autophagy is able to provide a minimal energy supply for tumour cell survival by degrading proteins. In addition, specific toxins, pathogens and altered cytoplasmic constituents, damaged cell organelles and aggregated proteins are sequestered and degraded through autophagy. The removal of these undesired materials supports tumour growth by protecting from apoptosis. In agreement with this suggestion is the observation that inhibition of autophagy can induce apoptosis of tumour cells (29). On the other hand, if cells cannot activate autophagy, protein synthesis predominates over protein degradation and cell growth continues; a situation that is typical of the cancer cells in the early stages of tumour growth. In this case, activation of autophagy could antagonise tumour growth. Apart from the stage of cancer, the level of cell differentiation, type of tissue, surrounding conditions and the genetic background influence autophagic activity in cancer $(8,30,31)$.

\section{Permeabilization of lysosomal membranes and apoptosis}

If ROS, lysosomotropic agents, or sphingosine accumulates within the lysosomes, they induce a variety of processes that may cause the destabilisation of the lysosomal membrane. 


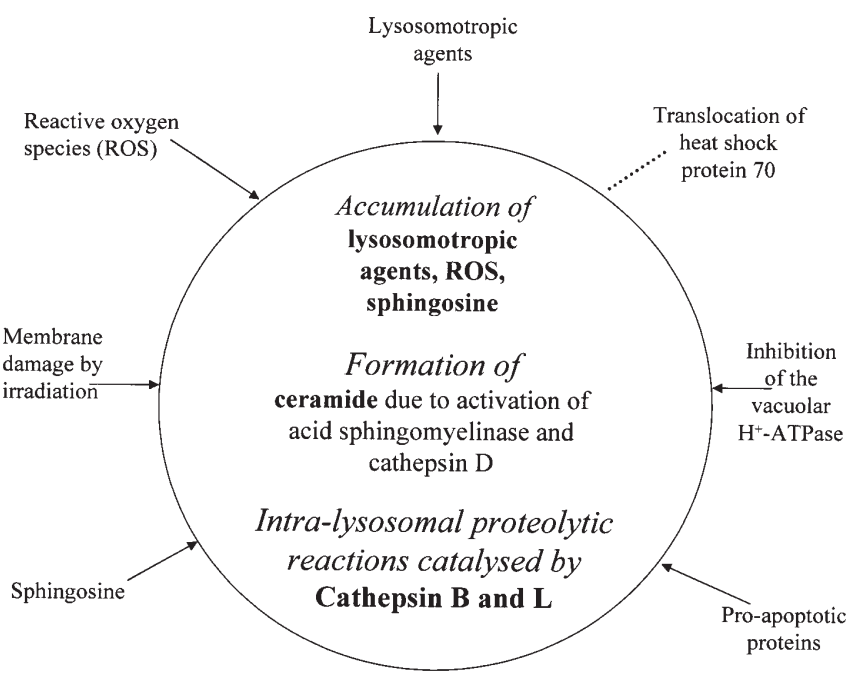

Total

Lysosomal permeabilisation (release of all lysosomal proteases)

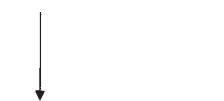

Necrosis

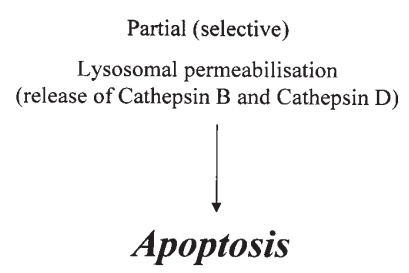

Figure 1. A current concept of lysosomal membrane permeabilisation, according to Guicciardi et al (7) modified.

Near total permeabilisation causes mainly necrotic cell death, while selective membrane permeabilisation induces mainly apoptosis (7). In Fig. 1, a current concept of lysosomal membrane permeabilisation is shown. For the destabilisation of the lysosomal membrane by ROS, intra-lysosomal ferric ions are essential, which originate from the digestion of iron-containing metalloproteins (32). The ferric ions catalyse the formation of oxygen radicals from hydrogen peroxide. Complexation of iron by deferoxamine stabilises lysosomes against hydrogen peroxide (33-35).

Irrespective of the cause of lysosomal membrane permeabilisation, if cathepsins are released from the lysosomal lumen into the cytoplasm they initiate a number of processes that may cause apoptosis. For example, they promote mitochondrial hydrogen peroxide formation (36). Since ROS are able to initiate lysosomal membrane permeabilisation, a positive feedback loop may be generated, if mitochondrial ROS formation is sufficiently high. Using 3-aminopropanal as lysosomal membrane disrupting agent, an amplifying loop presumably initiates, that is partially inhibited in the presence of $\alpha$-tocopherol (37).

Cathepsin B (a member of the cysteine proteinases) (38), and cathepsin D (a member of the small family of aspartate proteinases) mediate apoptosis in a variety of models (39-41). By using pepstatin (an aspartate proteinase inhibitor) the role of cathepsin D in apoptosis induction has been demonstrated. It prevented to different degrees apoptosis that was induced by anticancer drugs with lysosomotropic properties (42) and a newly synthesized retinoid (43).

Interestingly, the translocation of heat shock protein (HSP) 70 promotes cell survival by stabilising the lysosomal membrane and preventing its permeabilisation. The increased
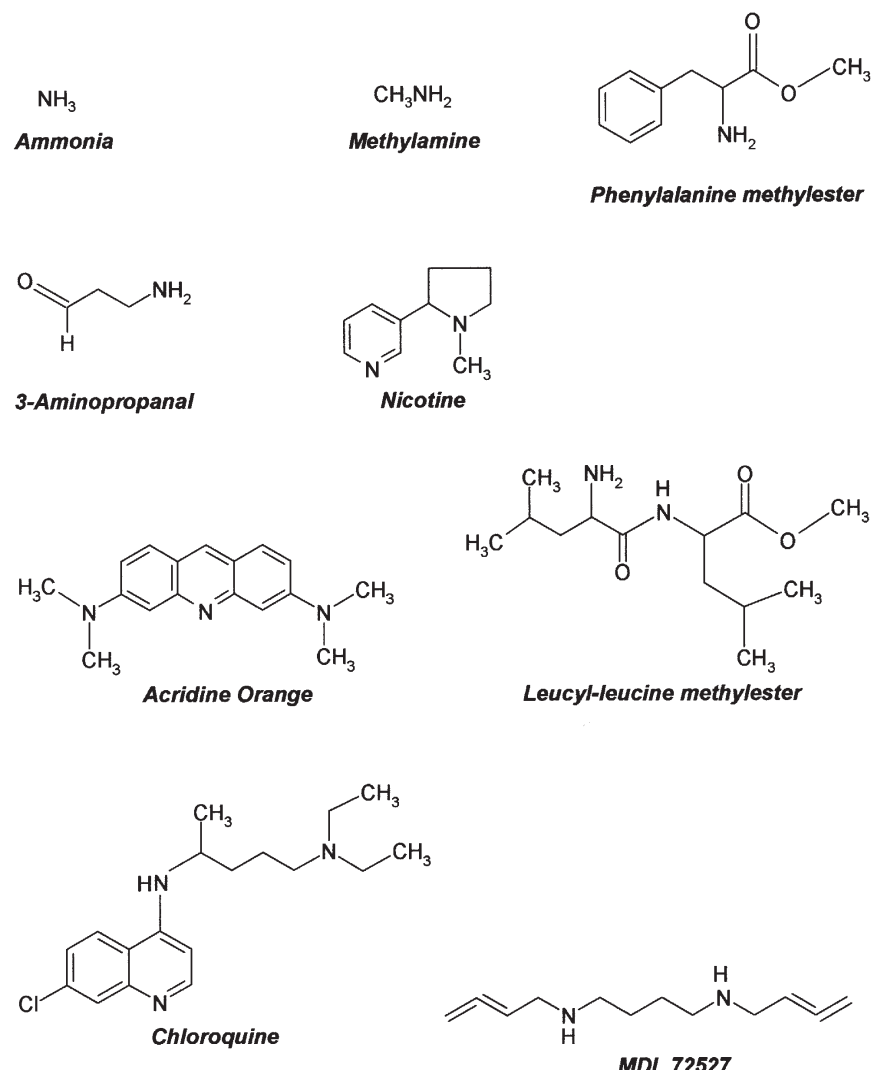

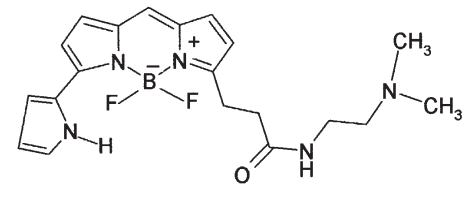

Lysotracker red
$M D L 72527$<smiles>CC(N)C#CC(C)N</smiles>

2,5-Diamino-3-hexyne
Figure 2. Structures of some selected lysosomotropic compounds.

formation and incorporation of HSP 70 into the lysosomal membrane is obviously a defence mechanism against stress, such as oxidative stress. It is well known that a variety of tumour cells generate an excess of ROS (44).

In view of the complexity of the apoptosis-related pathways and signalling cascades (1), an in-depth analysis of the consequences of lysosomal membrane permeabilisation is beyond the scope of this overview. However, it is evident from previous studies $(41,45)$ that mitochondrial membrane permeabilisation is a critical step of lysosome-initiated apoptosis. This was demonstrated, among others, by the following observations (46). After exposure to hydroxychloroquine, a lysosomotropic quinoline derivative, the release of cathepsin $\mathrm{B}$ from the lysosomal lumen was determined. Following the release of cathepsins, characteristic signs of apoptosis were observed, such as caspase activation, phosphatidylserine exposure, chromatin condensation, and mitochondrial permeabilisation, as indicated by insertion of Bax into mitochondrial membranes, the release of cytochrome $\mathrm{c}$, and the loss of mitochondrial transmembrane potential. Furthermore, mouse embryonic fibroblasts lacking the expression of Bax and Bak were resistant to hydroxychloroquine-induced apoptosis Although they released cathepsins similar to Bax and Bak expressing fibroblasts, they failed to undergo mitochondrial 
membrane permeabilisation. Kågedal et al (47) demonstrated by immunostaining that Bax inserts not only into the mitochondrial, but also into the lysosomal membrane, and causes the release of lysosomal proteases. It seems likely that the apoptotic effect of cathepsins is amplified by the impairment of the lysosomal membrane by Bax insertion.

\section{Lysosomotropy is not sufficient to kill cells}

Lysosomotropic compounds accumulate within the lysosomes owing to the $\mathrm{pH}$ gradient between the cytoplasm and the lysosomal lumen, hence they have to be proton acceptors. Since membranes are diffusion barriers for positively charged molecules, lysosomotropic compounds are usually weak bases with a considerable proportion of the free base in equilibrium with its protonated form. As shown in Fig. 2, their formula represents the diversity of structural features of lysosomotropic compounds. They range from simple aliphatic amines and amino acid esters to complex molecules. Compounds such as atropine, cocaine, nicotine and numerous other alkaloids, as well as the $\beta$-receptor blocker propanolol [1-(isopropylamino)3-(1-naphthyloxy)-2-propanol] belong to the family of lysosomotropic compounds. Acridine orange, Lysotracker red and other weakly basic fluorescent dyes accumulate selectively in acidic vesicles at low extracellular concentration, and allow the detection of leakage of acidic vesicular organelles by determining their relocation within the cytoplasm. Ammonia $\left(\mathrm{pK}_{\mathrm{B}} 4.75\right)$ and methylamine $\left(\mathrm{pK}_{\mathrm{B}} 3.40\right)$ are the most important endogenous lysosomotropic compounds. In the case of ammonium salts, $1.7 \%$ of $\mathrm{NH}_{3}$ is in equilibrium with $\mathrm{NH}_{4}{ }^{+}$at $\mathrm{pH}$ 7.4. Since the free bases, which enter the lysosomes by diffusion, are protonated within the lysosomal lumen, the intra-lysosomal $\mathrm{pH}$ increases; for example from 5.6-5.7 by approximately 1.4 units at $10 \mathrm{mM}$ ammonium chloride in the cellular environment. Owing to the increase of the intralysosomal $\mathrm{pH}$, the conditions for the proteolytic digestion of engulfed materials by the lysosomal enzymes are impaired. This has a number of consequences, including the prevention of the further uptake of lysosomotropic compounds, an increase in size and number of lysosomes, and the overloading of lysosomes by non-digestible material. The following few examples illustrate the consequences of a lysosomotropic compound accumulation in the cells. Tilorone, an immunomodulator, induces, in cultured fibroblasts, the lysosomal storage of sulphated glycosaminoglycans and produces cytological and histochemical alterations reminiscent of inheritable mucopolysaccharidosis (48). Treatment of peripheral blood lymphocytes with ammonia or other lysosomotropic compounds eliminates the natural killing activity of these cells similarly to the treatment with inhibitors of cathepsins (49). Ammonia and chloroquine reduce the catabolism of ${ }^{125}$ I-labeled Listeria by macrophages in a dose-dependent manner and affect an intracellular handling step required for the expression of the immunogenic that is relevant for $\mathrm{T}$ cell recognition (50). In fact, numerous drugs induce lysosomal disorders of the liver, since the Kuppfer cells accumulate lysosomotropic agents particularly well.

The impairment of protein digestion by lysosomotropic compounds may be exploitable for therapeutic purposes, as the following examples show. Monensin, a lysosomotropic peptide, improved the cytotoxicity of a conjugate of the ricin A chain, that was linked by a thioether bond to monoclonal antibodies directed toward breast cancer cells. Since the cellular transport of drugs is affected by lysosomes, a better understanding of their role in drug transport and compartmentalisation is expected to improve drug accumulation in clinically relevant sites (51).

Not all lysosomotropic compounds are cytotoxic. Ammonia salts, methylamine and related hydrophilic weak bases are mainly cytostatic. They cause swelling of the lysosomes, but do not render the membrane leaky to hydrolytic enzymes. In order to produce lysosomal membrane permeabilisation and cathepsin release, the lysosomotropic compounds require a certain degree of lipid solubility. The ability of lysosomotropic detergents to kill cells at low concentrations is due to their straight hydrocarbon chain tail of 9-14 carbon atoms that is usually attached to imidazole, morpholine and related bases (52). These compounds are incorporated into membranes and impair membrane stability.

Since, however, highly lipophilic compounds impair membrane function indiscriminately, they are not useful as drugs. That their accumulation is nevertheless important for their membrane effects is demonstrated by the observation that ammonia, methylamine and other non-cytotoxic lysosomotropic compounds provide protection against lysosomotropic detergents.

\section{Inhibitors of vacuolar ATPases mimic effects of lysosomotropic compounds}

Proton pumps, namely the vacuolar-type ATPases (VATPases), maintain the $\mathrm{pH}$ gradient between cytoplasm and acidic vesicles. Inhibitors of the V-ATPases, such as the plecomacrolide antibiotics bafilomycin $\mathrm{A}$ and the concanamycins, increase the intra-lysosomal $\mathrm{pH}$ similarly to lysosomotropic compounds (53).

The V-ATPase inhibitors are cytotoxic toward a variety of tumour cells; $\mathrm{EC}_{50}$ values are in the nanomolar range. They even have anti-tumour properties in vivo (54-56). The release of cathepsin D into the cytoplasm by V-ATPase inhibitors produces the characteristic signs of apoptotic cell death, including caspase-3 activation and DNA laddering. However, as pointed out by Nakashima et al (55), bafilomycin Al induced neither a decrease of the mitochondrial transmembrane potential, nor the release of cytochrome c, indicating a mitochondrion-independent death mechanism.

\section{Cytotoxic lysosomotropic compounds}

Lysosomal cathepsins induce cell death. Since the release of lysosomal cathepsins induces apoptotic and non-apoptotic (necrotic) cell death $(7,12)$, the permeabilisation of the lysosomal membrane appears to be a potential target in cancer therapy.

For the destabilisation of the lysosomal membrane, in principle two methods of therapeutic potential are available: formation of ROS, for instance by UV or $\gamma$-irradiation, or by enzymatic reactions using xanthine oxidase after administration of hypoxanthine (57) or by bovine serum amine oxidase (BSAO) administration in the presence of spermine (58), and 
Table I. Lysosomotropic compounds with cytotoxic properties.

\begin{tabular}{|c|c|c|}
\hline Compound & Cells & Reference \\
\hline N-dodecyl-imidazol & Baby hamster kidney (BHK) & Miller et al (52) \\
\hline Chloroquine & $\begin{array}{l}\text { Pancreatic adenocarcinoma } \\
\text { Human metastatic colon carcinoma SW } 620\end{array}$ & $\begin{array}{l}\text { Zeilhofer et al (63) } \\
\text { Seiler } \text { et al (64) }\end{array}$ \\
\hline Hydroxychloroquine & & Boya et al (45) \\
\hline $\begin{array}{l}\text { MDL } 72527 \\
{\left[\mathrm{~N}^{1}, \mathrm{~N}^{4} \text {-bis (2,3-butadienyl)-1,4-butanediamine }\right]}\end{array}$ & $\begin{array}{l}\text { Human metastatic colon carcinoma SW } 620 \text { and } \\
\text { SW } 480 \\
\text { L1210 mouse leukemia } \\
\text { LoVo colon adenocarcinoma and M14 melanoma }\end{array}$ & $\begin{array}{l}\text { Duranton et al }(73) \\
\text { Dai et al }(19) \\
\text { Seiler } \text { et al }(72) \\
\text { Agostinelli } \text { et al }(74,75)\end{array}$ \\
\hline $\mathrm{N}^{1}, \mathrm{~N}^{4}$-di-n-butyl-1,4-butanediamine & $\begin{array}{l}\text { L1210 mouse leukemia } \\
\text { Human metastatic colon carcinoma SW } 620\end{array}$ & Seiler et al (72) \\
\hline $\begin{array}{l}\text { 1,4-diamino-2-butyne } \\
\text { 2,5-diamino-3-hexyne }\end{array}$ & L1210 mouse leukemia & Porter et al (108) \\
\hline Phenylalanine methylester & Human leukemia & Rosenfeld (109) \\
\hline Glycyl-D-phenylalanine-2-naphthalamide & Vero cells & Jadot et al (110) \\
\hline L-leucyl-L-Leucine methylester & Human leukaemia (HL60) & $\begin{array}{l}\text { Uchimoto et al }(111) \\
\text { Mizuta et al (112) }\end{array}$ \\
\hline $\begin{array}{l}\text { Retinoid CD437 (6-[3-(1-adamantyl)-4-hydroxyphenyl]- } \\
\text { 2-naphthalene carboxylic acid) }\end{array}$ & $\begin{array}{l}\text { Human leukaemia (HL60) and several other } \\
\text { tumour cell lines }\end{array}$ & Zang et al (43) \\
\hline Tilorone (2,7-bis[2-(diethylamino) ethoxy]fluoren-5-one) & Bovine fibroblasts & Lullmann-Rauch et al (113) \\
\hline 3-Aminopropanal & $\begin{array}{l}\text { D384 glioma } \\
\text { Human neuroblastoma (SH-Sy5Y) }\end{array}$ & $\begin{array}{l}\text { Li et al }(114) \\
\text { Yu et al }(37)\end{array}$ \\
\hline Ciprofloxacin, Norfloxacin & HeLa cells & Boya et al (46) \\
\hline
\end{tabular}

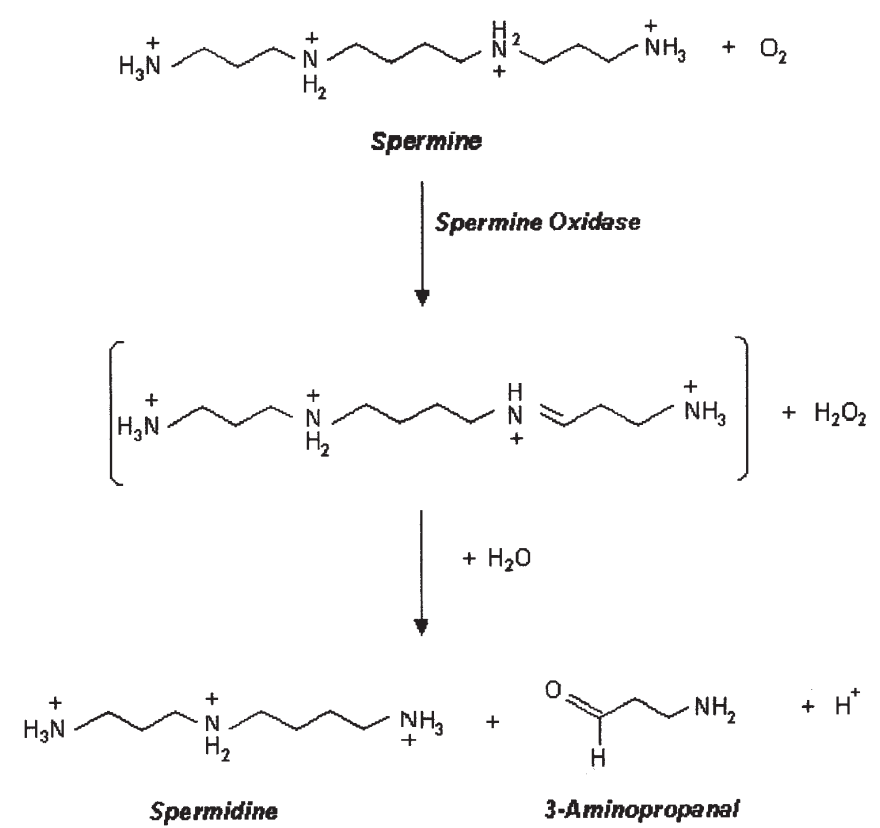

Figure 3 . Formation of 2-aminopropanal from spermine by the spermine oxidase-catalysed reaction.

lysosomal membrane permeabilisation by lysosomotropic compounds [the fact that lysosomotropic compounds may induce ROS formation (59) is not considered as a third method]. In contrast to irradiation methods, therapies relying on ROS formation by enzyme-catalysed reactions and the administration of lysosomotropic compounds have not been systematically explored.

Several conventional drugs may be capable of releasing cathepsins by permeabilising lysosomal membranes. Indeed, numerous anticancer drugs induce DNA damage that triggers p53-dependent apoptosis, and Yuan et al (60) demonstrated that p53-mediated apoptosis is induced via lysosomal damage by ROS.

Among 879 compounds of the National Cancer Institute mechanistic set, 15 induced caspase-catalysed cleavage of cytokeratin-18, without showing dependence on p53 induction. Among this subset, seven compounds showed lysosomal membrane permeabilisation (42). Their anticancer effect is likely to rely at least in part on this property. Since over 50\% of human tumours contain a functionally defective p53 that reduces sensitivity to some commonly used chemotherapeutic agents, such as etoposide and cisplatin, apoptotic p53independent drugs may have an advantage.

In Table I, lysosomotropic compounds of known cytotoxicity are compiled. Some selected compounds are more closely considered below.

3-Aminopropanal. 3-Aminopropanal is a potent lysosomotropic compound that causes oxidative stress by rupturing lysosomes 
(37). It is a polyamine metabolite in cerebral ischemia (61) and attracts particular interest as an endogenous compound with neurotoxic properties. Although its formation has not been entirely clarified, it seems likely to be a product of spermine oxidase, an inducible flavin-dependent amine oxidase (62). This reaction is formulated in Fig. 3, but another flavindependent polyamine oxidase (PAO) may also promote the formation of 3-aminopropanal from spermine. Other not yet identified amine oxidases cannot be excluded from being responsible for the formation of this toxic aldehyde, from spermidine or spermine, in the brain of stroke patients.

Chloroquine. Chloroquine, an anti-malaria and anti-inflammatory drug, is known for its lysosomotropic properties. It is cytotoxic, with $\mathrm{EC}_{50}$ values in the $\mu \mathrm{M}$ range $(63,64)$. It synergises the cytotoxic effect of polyphenolic apple constituents, the procyanidins, in SW 620 metastatic colon carcinoma cells (64) and of Vinca alkaloids and anthracyclines in MDR human leukaemia and KB carcinoma cells $(65,66)$. Other lysosomotropic amines, such as propanolol, atropine, amantadine and nicotine were also effective in restoring the sensitivity of the carcinoma cells to vincristine, vinblastine and actinomycin D cytotoxicity (66).

$N^{1}, N^{4}$-bis(2,3-butadienyl)-1,4-butanediamine (MDL 72527). MDL 72527 and some structurally related diamines with unsaturated aliphatic substituents had been designed as inactivators of polyamine oxidase (PAO), an enzyme present in most vertebrate tissues and responsible for the interconversion of the polyamines (67). The compound enhances the cytotoxicity of spermine to baby hamster kidney (BHK) (68) and CaCo-2 cells (69), as well as the cytotoxicity of a calmodulin antagonist to several tumour cell lines $(70,71)$. In the course of these investigations, it became apparent that the cytotoxic effect of MDL 72527 was independent of its ability to inactivate PAO. This was later confirmed by the comparison with a saturated structural analogue, which lacked the ability to inhibit PAO (72). The observations of Dai et al (19) revealed the apoptotic and lysosomotropic property of the drug. The latter was based on the formation of cytoplasmic vacuoles. Dai et al (19) demonstrated also a high sensitivity of transformed haematopoietic cells (in comparison with the non-transformed analogues) to MDL 72527. Vacuole formation and induction of apoptosis was also shown for colon carcinoma-derived SW 480 and SW 620 cell lines $(72,73)$ and for wild-type and MDR LoVo human colon adenocarcinoma (74) and M14 melanoma cells (75), when they were pretreated with MDL 72527 and then treated with BSAO in the presence of spermine. However, in contrast with the latter observations on LoVo and M14 cells, vacuole formation in leukaemia cells (19) was not reversible in the presence of MDL 72527.

\section{Sensitisation of cancer cells to anticancer treatment by lysosomotropic compounds}

Cross-resistance of cells to cytotoxic actions of a wide variety of natural and synthetic anticancer drugs is the wellknown phenomenon called multidrug resistance (MDR). The pharmacological basis of MDR is the decreased accumulation and enhanced release of the cytotoxic drugs. The development<smiles>CCC(C#N)(CCCN(C)CCc1ccc(OC)c(OC)c1)C(C)C</smiles><smiles>CN(C)CCC(Oc1ccc(C(F)(F)F)cc1)c1ccccc1</smiles>

Fluoxetine

Figure 4. Structural formulae of Verapamil and Fluoxetine, drugs that reverse multidrug resistance.

of MDR is associated with the overexpression of a gene that encodes an integral membrane glycoprotein of $170 \mathrm{kDA}$, called glycoprotein P, for its structure see Loo and Clarke (76). Glycoprotein P functions as an ATP-dependent pump that extrudes a broad range of drugs from the cells $(77,78)$.

A variety of stimuli increase the expression of the MDR gene: low extracellular $\mathrm{pH}$, heat shock, arsenite and other cytotoxic agents including anticancer drugs and UV irradiation, among others (79). Wadkins and Roepe (80) drew attention to the changes of intracellular $\mathrm{pH}$ and membrane potential of cells with overexpressed P-glycoprotein. These changes affect the transmembrane flux of a large number of compounds, which render the cells drug resistant.

In an attempt to characterise the physical and chemical properties shared by compounds that modulate MDR, Zamora et al (81) established a long list of structures including synthetic and natural indoles, acridines, quinolines, isoquinolines and alkaloids containing these structures as well as numerous other alkaloids, among which nicotine and atropine should be mentioned here. According to these and other investigations, chemosensitisers with the capacity to block drug extrusion have to contain hydrophobic parts and aromatic moieties, and a functional group that can act as a hydrogen bond donor or acceptor (78). They are lipid soluble at physiological $\mathrm{pH}$ and many of these compounds possess a basic nitrogen atom and at least two co-planar aromatic rings (79). Verapamil (a $\mathrm{Ca}^{2+}$ ion channel blocker) is considered as one of the most potent chemosensitisers (Fig. 4). It is frequently used as standard for determinations of the ability of new compounds to reverse MDR (82-85).

Binding of vinblastine to membrane vesicles from MDR cells, produced by exposure to Vinca alkaloids or anthracyclines, and competition for the binding site suggested binding to P-glycoprotein as the characteristic property of compounds suited to reverse MDR. Binding of chemosensitisers to the P-glycoprotein pump has repeatedly been demonstrated. For example, chloroquine inhibits the photo affinity labelling of a quinoline-based photoactive chemosensitiser (N-\{4-[1hydroxy-2-(dibutylamino)ethyl]quinolin-6-yl\}-4-azidosalicylamide) (86). 
Zamora et al (81) directed attention to the fact that Verapamil has lysosomotropic properties: this is evident from its ability to prevent intra-lysosomal proteolysis $(87,88)$. From a structural point of view, many of the compounds listed by Zamora et al (81) have the structural features of lysosomotropic compounds. This is also true for more recently investigated chemosensitisers, such as Fluoxetine (N-methyl-3-[(4-trifluoromethyl)phenoxy]benzene-propanamine), an antidepressant with structural similarity to Verapamil, and several other compounds (Fig. 4) (83-85). Owing to their hydrophobic parts, these bases are presumed to impair lysosomal membrane stability. Presumably, a polymer of spermine that is likely to accumulate in lysosomes after having been taken up by endocytosis, belongs also to this group (89).

From the foregoing, it seems evident that, among the MDR-reversing drugs, selective ligands of P-glycoprotein are more rare than the norm, since most of the compounds have the structural features of lysosomotropic compounds. The following observation supports the suggestion that chemosensitisers may not exclusively (and in some cases not at all) act by binding to P-glycoprotein: Verapamil and reserpine greatly improve the cytotoxic effect of Taxol, anthracyclines and Vinca alkaloids in P-glycoprotein-deficient hamster and human nasopharyngeal carcinoma cells (90). In this case, binding to P-glycoprotein is excluded as a mechanism of sensitisation. The sensitising effect of Verapamil is not stereospecific, i.e. the $\mathrm{R}$ - and $\mathrm{S}$-isomers are equipotent in modulating resistance in L1210 mouse leukaemia cells by Mitomycin C, an alkylating agent (91). This fact may also be taken as a hint to a chemosensitising mechanism of Verapamil that is independent of P-glycoprotein binding.

Lysosomotropy appears to be a more general principle of drug sensitisation than binding to P-glycoprotein, though certainly not an exclusive principle. Lysosomotropic drugs and lipophilic compounds, including neutral detergents $(92,93)$, have in common that they impair membrane fluidity, stability and permeability. In agreement with the notion that membrane permeabilisation is a key step in drug-induced sensitisation of cells to anticancer drugs is the observation that the ability of drugs to enhance Taxol cytotoxicity correlates with their ability to permeabilise lipid bilayers (90).

8. Hydrogen peroxide and spermine oxidation products induce damage of lysosomal membrane and multidrugresistant cells

In vitro and in vivo studies on $\mathrm{BSAO} /$ spermine-induced cytotoxicity. Hydrogen peroxide damages lysosomal membranes and initiates apoptosis (35). Likewise, hydrogen peroxide formed in situ, e.g. by enzymatic oxidation of hypoxanthine (57) or spermine (58), is cytotoxic and has anti-tumour effects in vivo $(57,94)$.

Several in vitro studies have shown that the cytotoxic products of BSAO and spermine, $\mathrm{H}_{2} \mathrm{O}_{2}$ and acrolein, can induce either apoptosis or necrosis, depending on both their concentrations and the cell type $(58,95-98)$. The cytotoxicity was evaluated on both sensitive and resistant human colon adenocarcinoma cells (LoVo WT and LoVo DX, respectively) and melanoma cells (M14 WT and the doxorubicin-resistant line M14 ADR) by using a plating efficiency assay, thus

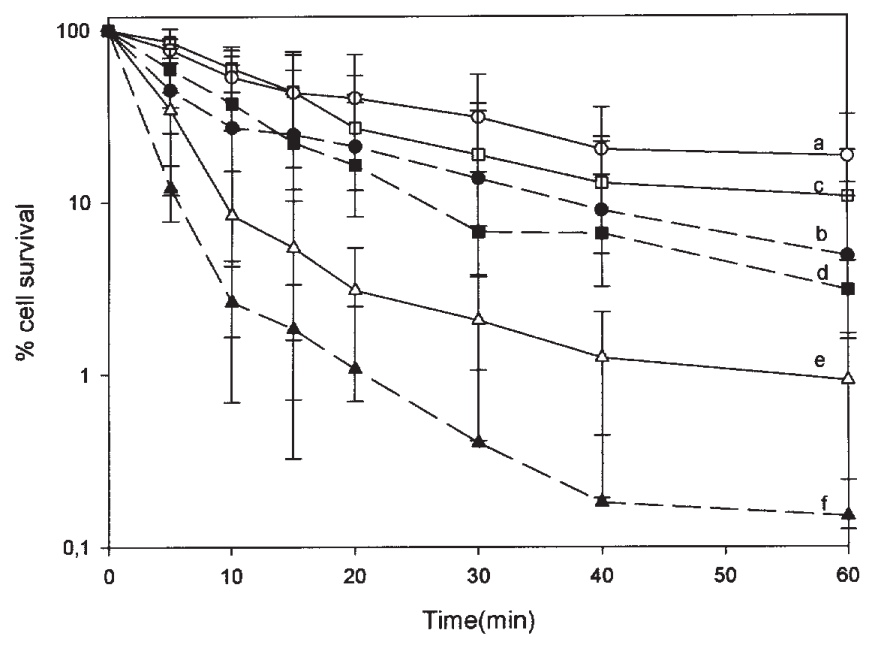

Figure 5. Effect of BSAO in the presence of spermine on the survival of M14 melanoma and LoVo colon adenocarcinoma cells, WT (solid line) and MDR (dashed line). Time-effect relationship and effect of different concentrations of spermine on cell survival. M14 WT and M14 ADR cells were incubated in the presence of $6.5 \times 10^{-3} \mathrm{IU} / \mathrm{ml} \mathrm{BSAO}$ and $6 \mu \mathrm{M}$ spermine ( $\square$; $\boldsymbol{\square})$ for up to $60 \mathrm{~min}$ at $37^{\circ} \mathrm{C}$, followed by the determination of the percentage of surviving cells by a plating efficiency assay. LoVo WT and LoVo DX cells were also incubated in the same experimental conditions with $6 \mu \mathrm{M}$ spermine $(\circ ; \bullet)$ and $12 \mu \mathrm{M}$ spermine $(\triangle ; \mathbf{\Delta})$. Each point represents the mean value of the results of 2 to 5 plates of three or four experiments. The error bars indicate \pm S.D. When not shown, S.D. lies within the symbols.

determining the ability of the cells to reproduce and form macroscopic colonies.

Fig. 5 shows the percentage cell survival against the time of exposure to purified BSAO $\left(6.98 \times 10^{-3}\right.$ units $\left./ \mathrm{ml}\right)$ in the presence of exogenous spermine $(6$ and $12 \mu \mathrm{M})$, at $37^{\circ} \mathrm{C}$. In the presence of BSAO and spermine, a higher cytotoxicity was observed in LoVo DX than in LoVo WT cells. The percentage cell survival decreased in both cell lines with increasing exposure time, resulting in approximately $18 \%$ in LoVo WT (curve a) and approximately 5\% in LoVo DX cells (curve b), after 60 min of incubation. Also M14 ADR cells were more sensitive to the treatment than M14 WT cells. The cytotoxic effect on both cell lines increased as a function of incubation time. After 60 min of incubation, which is the highest incubation time, the survival of M14 WT cells was approximately $11 \%$ (curve c), while only 3\% (curve d) of the M14 ADR cells remained viable. As expected, it may be seen that the cytotoxic effect in LoVo WT (curve e) and LoVo DX cells (curve f) was more marked in the presence of $12 \mu \mathrm{M}$ spermine than $6 \mu \mathrm{M}$ spermine, at $37^{\circ} \mathrm{C}$. The higher cytotoxicity in the presence of $12 \mu \mathrm{M}$ spermine was attributed to the formation of an increased amount of $\mathrm{H}_{2} \mathrm{O}_{2}$ and aldehyde(s), during the enzymatic reaction $(74,75)$. It was determined fluorometrically that approximately $80 \%$ of the formed $\mathrm{H}_{2} \mathrm{O}_{2}$ crossed the cell membrane, and that uptake reached a maximum in approximately $10 \mathrm{~min}$ after the enzymatic reaction was started. Aldehyde(s) contributed to cytotoxicity, but at a later stage of the reaction and to a lower extent (approximately 20\%) (98).

A considerable enhancement of cytotoxicity at $42^{\circ} \mathrm{C}$, compared to $37^{\circ} \mathrm{C}$, was also determined. In hyperthermic conditions greater cytotoxicity was observed in MDR cells than in sensitive cells, in both colon adenocarcinoma and 


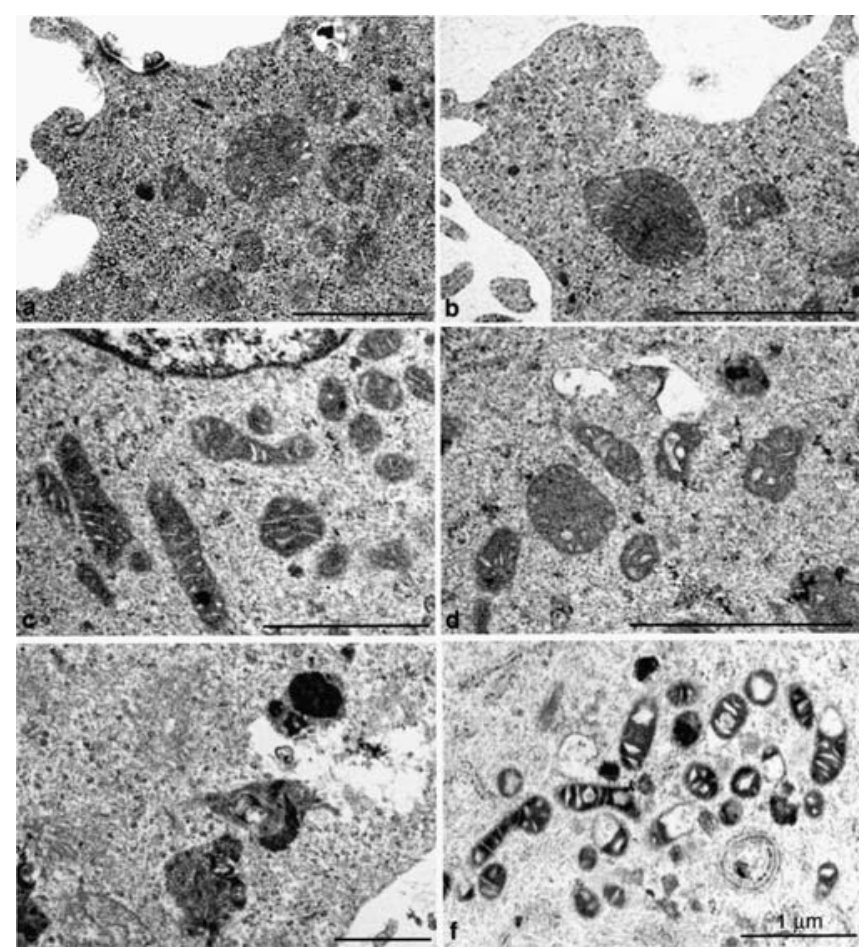

Figure 6. Ultrastructural features of mitochondria of M14 WT and M14 ADR cells (transmission electron micrographs). (a) Untreated M14 WT cells. (b) Untreated M14 ADR cells. (c) M14 WT cells and (d) M14 ADR cells exposed for $60 \mathrm{~min}$ to $6.5 \times 10^{-3} \mathrm{IU} / \mathrm{ml} \mathrm{BSAO}$ and $6 \mu \mathrm{M}$ spermine at $37^{\circ} \mathrm{C}$. (e) M14 WT and (f) M14 ADR pre-treated cells with $300 \mu \mathrm{M}$ MDL 72527 for $6 \mathrm{~h}$ and then treated with BSAO and $6 \mu \mathrm{M}$ spermine for $60 \mathrm{~min}$. The alterations of the mitochondrial structure are more evident in treated M14 ADR cells. Scale bars, $1 \mu \mathrm{m}$.

melanoma cell lines. Hyperthermia could act at the initial stage of the treatment, probably by accelerating the kinetics of the membrane molecular interactions and by favouring drug delivery into the cancer cells $(99,100)$.

Preliminary results obtained on LoVo WT and LoVo DX cells by real-time PCR experiments, showed an increase in mRNA levels for the BAX pro-apoptotic gene in MDR cells after treatment with $12 \mu \mathrm{M}$ exogenous $\mathrm{H}_{2} \mathrm{O}_{2}$ of both LoVo cell lines. Instead, LoVo cells treated during $60 \mathrm{~min}$ of incubation with $12 \mu \mathrm{M}$ exogenous acrolein, showed a slight overexpression of the pro-apoptotic gene BAX at the latest stage of the reaction, in agreement with the results obtained by the clonogenic assay, as above described. The pro-survival BCL-2 gene did not reveal any variation after LoVo cell line treatment with either exogenous $\mathrm{H}_{2} \mathrm{O}_{2}$ or acrolein (Agostinelli, manuscript in preparation).

Taking into account these findings, it has been therefore evaluated in vivo, using a mouse melanoma model, whether $\mathrm{BSAO}$, when injected directly into the tumour, is able to induce tumouricidal activity by converting endogenous polyamines to toxic products in situ (94). Treatment of mice bearing subcutaneous melanoma tumours with a low dose $(2.5 \mathrm{mU})$ of native or immobilized BSAO, induced inhibition of tumour growth by $40 \%$ and $70 \%$, respectively, during a period of 10 days after a single injection of the enzyme into the center of the tumour. The poly-ethylene glycol (PEG)-albumin matrix used for enzyme immobilization had no significant effect on tumour growth. The lower $\mathrm{V}_{\max }$ of the immobilized form of BSAO would allow a prolonged, slow release of cytotoxic products compared to the more rapid generation of higher levels of cytotoxic products with the native enzyme. Moreover, it was reported that the immobilization of BSAO into a hydrogel matrix of PEG-albumin increased its operational stability in vitro from $1.5 \mathrm{~h}$ to $70 \mathrm{~h}$ (101). An important finding is that, under these experimental conditions, the native BSAO generates a burst of hydrogen peroxide and aldehyde(s) at such concentrations that necrosis is favoured, whereas immobilized BSAO caused cell death mainly by apoptosis.

The main goal of this study is to develop a new type of cancer treatment for solid tumours, which takes advantage of the fact that the polyamine levels are higher in many solid tumour tissues such as breast, colon, melanoma, brain and kidney (102). These findings with immobilized BSAO could be beneficial since the ultimate aim of anticancer treatments is to induce tumour cell death by apoptosis, a process that avoids inflammatory damage to surrounding tissues.

Sensitization of LoVo and M14 cells to BSAO/spermineinduced toxicity by $M D L$ 72527. At present, we are investigating drug combinations with the aim to increase the induction of cell death by toxic polyamine metabolites. It has been demonstrated that pre-treatment of human colon cancerderived LoVo (74) and M14 human melanoma cells (75) with MDL $72527\left[\mathrm{~N}^{1}, \mathrm{~N}^{4}\right.$-bis(2,3-butadienyl)-1,4-butanediamine dihydrochloride] sensitizes the cells to subsequent exposure to hydrogen peroxide and aldehydes generated from $\mathrm{BSAO} /$ spermine-induced cell death and potentiates the enzymatic system. In Fig. 6, transmission electron microscopy (TEM) observations showed that the pre-treatment of the cells with $300 \mu \mathrm{M}$ MDL 72527 caused the temporary formation of cytoplasmic vacuoles, of lysosomal origin, within less than $6 \mathrm{~h}$ (Fig. 6e and f). The pre-treatment with MDL 72527 also increased the number of lysosomal structures as shown by confocal microscopy (Fig. 7c and d; Agostinelli et al, manuscript in preparation) when compared with the controls (Fig. 7a and $b$ ), indicating a contribution of the lysosomotropic properties of MDL 72527 to the sensitisation of the tumour cells to hydrogen peroxide and aldehyde formed during the treatment with BSAO and spermine (Fig. 6e and f). Instead, mitochondrial damage, as observed by TEM (Fig. 6c and d), seemed to correlate better with the cytotoxic effects induced by the ROS generated during the treatment than with the formation of vacuoles. A direct cytotoxic effect of spermine at low concentrations used in these experiments can be excluded. In essence, the ultrastructural alterations support the view that MDL 72527 acts as a lysosomotropic compound and that the sensitization of M14 melanoma or LoVo colon adenocarcinoma cells to the treatment with BSAO and spermine, as was evident from the decrease of cell survival, is mainly due to the effects induced by pre-treatment with MDL 72527 on the endosomal-lysosomal system, with release of lysosomal enzymes into the cytosol $(74,75)$. The MDR cell lines deriving from LoVo and M14 cells were considerably more sensitive to this treatment than the corresponding wildtype cell lines. In fact, severe changes of the mitochondrial structure, such as dilatation of the cristae and disruption of membranes, were mainly observed in multidrug-resistant cells 

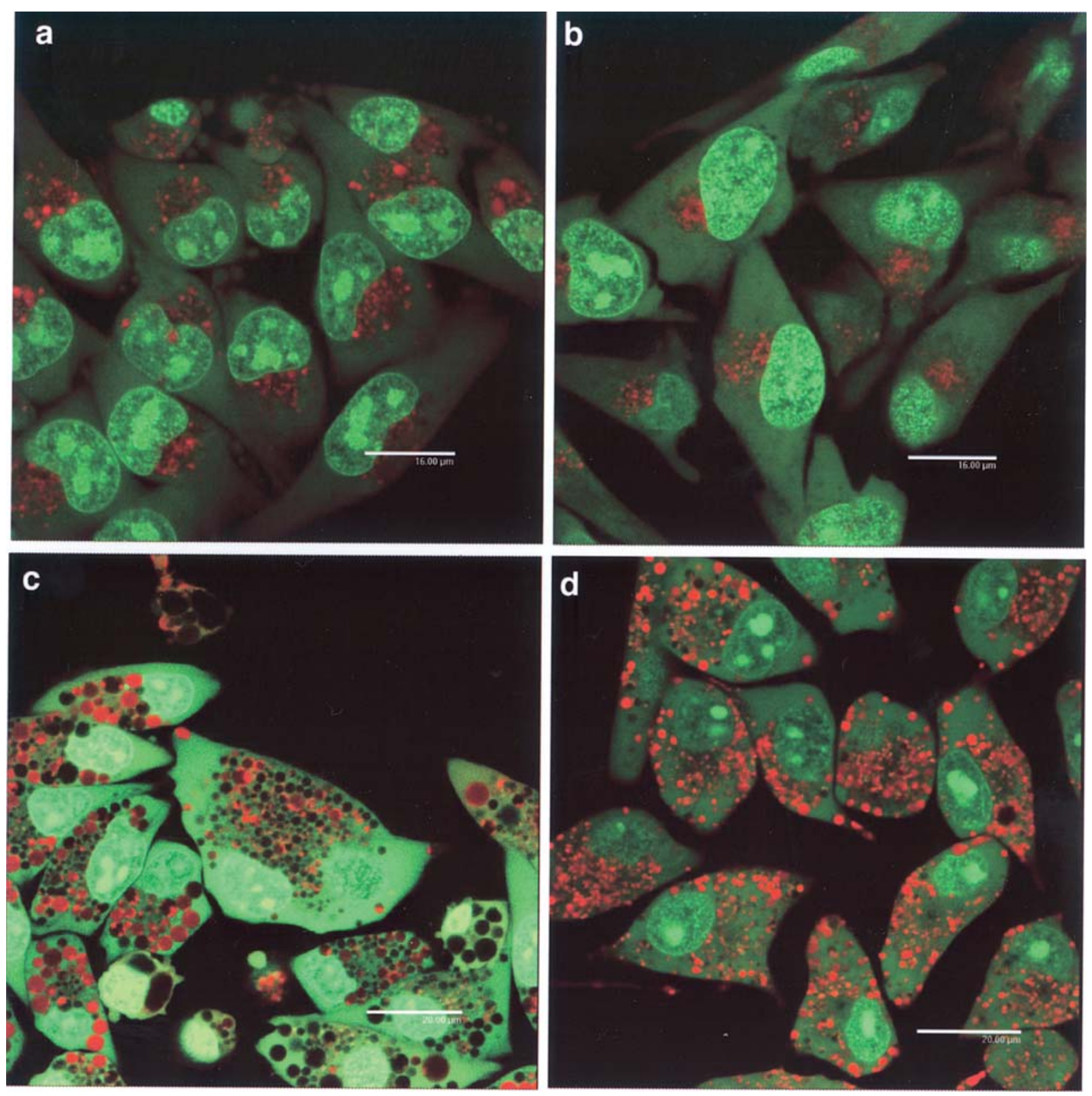

Figure 7. Confocal microscopy observations. The pre-treatment with $300 \mu \mathrm{M}$ MDL 72527 enhanced the number of lysosomal structures. (a) Untreated M14 WT cells. (b) Untreated M14 ADR cells (scale bars, $16 \mu \mathrm{m}$ ). (c) M14 WT and (d) M14 ADR treated cells (300 $\mu$ M MDL 72527 for $6 \mathrm{~h}$ ) (scale bars, $20 \mu \mathrm{m}$ ). The number of lysosomes was higher in M14 ADR than in WT cells.

(Fig. 6d and f). The results represent an important aspect for the application of this strategy, since the occurrence of resistance to cytotoxic agents in cancer cells is one of the most serious obstacles to successful anticancer chemotherapy (77). Although MDL 72527 is likely to be a substrate of the P-glycoprotein pump, as determined by flow cytometry and immunofluorescence confocal microscopy, the higher sensitivity of MDR LoVo and M14 cells to hydrogen peroxide toxicity cannot be explained by the differences of the activity of the P-glycoprotein pump. Presumably, the previously mentioned changes of the physical properties of the cells (altered intracellular $\mathrm{pH}$ and membrane potential) due to the overexpression of the MDR gene (80) offer a basis for an explanation of the observed sensitization of MDR cells to hydrogen peroxide, the enzymatic oxidation product of polyamines. However, this aspect is presently being investigated.

\section{Concluding remarks}

The revival of interest in lysosomal function accompanies the 50th anniversary of the discovery of lysosomal function (21), as already pointed out in the introduction to this review. From the enhanced sensitivity of immortalised cells to lysosomal death pathways (103), new possibilities in cancer therapy are expected (11). Lysosomotropic compounds were not included in these considerations, and played in fact an outsider role during the last decades. However, the sensitisation of tumour cells to anticancer drugs by lysosomotropic compounds, and particularly the sensitisation of MDR-resistant cells, recommend scrutinizing the potential of lysosomotropic drugs in cancer therapy. Admittedly, there are some obvious problems to be taken into consideration. a) The stabilisation of lysosomal membranes by translocation of HSP 70 seems 
to argue against the use of lysosomotropic compounds, because it decreases the sensitivity to cytotoxic lysosomotropic compounds. Presently, information is lacking on the relative sensitivity of non-transformed and transformed cells to the combined treatment with anticancer drugs and compounds that destabilise lysosomal membranes and favour cathepsin D release. The observation of Dai et al (19) on the higher sensitivity to MDL 72527 of leukaemia cells, compared with immortal myeloid progenitor cells, is promising for therapeutic applications of cytotoxic lysosomotropic compounds. b) The impairment of lysosomal proteolysis prevents chronic treatment, but this should not be too great a hurdle, as is evident from the extensive experience with chloroquine in the treatment of malaria.

From a therapeutic point of view, the improvement of the efficacy of in situ formation of cytotoxic polyamine metabolites is essential. This may be achieved by combinations of the treatment with cytotoxic drugs, or by heat. Hyperthermia in combination with cytotoxic drugs (100), preferentially with drugs that enhance cytotoxicity at elevated temperatures (104), and the administration of drug combinations are clinically accepted methods. Likewise, sensitising cells by a lysosomotropic compound, as for example chloroquine or MDL 72527 $(74,75)$, improved cell damage by hydrogen peroxide and other spermine metabolites. An extension of these experiments with the aim to further improve the cytotoxic effect of spermine metabolites appears important.

Based on the structural requirements of the chemosensitisers, which are similar to those of cytotoxic lysosomotropic compounds, a rational design of new cytotoxic lysosomotropic compounds is possible and desirable. However, new compounds are not absolutely required, since promising clinical trials could be started immediately using combinations of available drugs. In the first place, well-established drugs with known toxicological and pharmacological properties should be taken into consideration. Among these, Fluoxetine has an interesting aspect for cancer treatment because of its antidepressant properties. In our opinion, the systematic exploration of chloroquine in combination with conventional anticancer drugs promises new, efficient anticancer therapies within a short period. This compound is cytotoxic per se and because of its scanty side effects it can be used even in longterm treatments of children (105). In addition, chloroquine has antiviral effects (106) and, more important, it improves the therapy of glioblastoma multiforme (107). In our laboratory, preliminary studies carried out on human colon adenocarcinoma and melanoma cells suggest that the antimalarial drug chloroquine, in association with $\mathrm{BSAO} /$ spermine, could potentiate the effects of the enzymatic oxidation products of spermine and might be important as a new approach in antineoplastic therapy, particularly against MDR cancer cells.

\section{Acknowledgements}

This review is dedicated to Professor Nikolaus Seiler. The original work reported here was partially supported by the Italian MIUR (Ministero dell'Istruzione, dell'Università e della Ricerca) and by funds MIUR-PRIN (Cofin) (EA). Thanks are due to Dr Arancia, Istituto Superiore Sanità, Italy, for joint collaboration in electron microscopy studies.

\section{References}

1. Hengartner MO: The biochemistry of apoptosis. Nature 407: 770-776, 2000 .

2. Fulda $\mathrm{S}$ and Debatin KM: Exploiting death receptor signalling pathways for tumor therapy. Biochim Biophys Acta 1795: 27-41, 2004.

3. Jäättelä M: Multiple cell death pathways as regulators of tumour initiation and progression. Oncogene 23: 2746-2756, 2004.

4. Broker LE, Kruyt FA and Giaccone G: Cell death independent of caspases: a review. Clin Cancer Res 11: 3155-3162, 2005

5. Kroemer G and Martin SJ: Caspase-independent cell death. Nat Med 11: 723-730, 2005

6. Castino R, Demoz M and Isidoro C: Destination 'lysosome': a target organelle for tumor cell killing. J Mol Recognit 16: $337-348,2003$.

7. Guicciardi ME, Leist M and Gores GJ: Lysosomes in cell death. Oncogene 23: 2881-2890, 2004.

8. Cuervo AM: Autophagy in sickness and in health. Trends Cell Biol 14: 70-77, 2004.

9. Eskelinen EL: Doctor Jekyll and Mister Hyde: Autophagy can promote both cell survival and cell death. Cell Death Differ 12: 1468-1472, 2005.

10. Kroemer G and Jäättelä M: Lysosomes and autophagy in cell death control. Nat Rev Cancer 5: 886-897, 2005.

11. Fehrenbacher N and Jäättelä M: Lysosomes as targets in cancer therapy. Cancer Res 65: 2993-2995, 2005.

12. Stoka V, Turk B and Turk V: Lysosomal cysteine proteinases: structural features and their role in apoptosis. IUBMB Life 57: 347-353, 2005.

13. Kane SE and Gottesman MM: The role of cathepsin L in malignant transformation. Semin Cancer Biol 1: 127-136, 1990.

14. Koblinski JE, Ahram M and Sloane BF: Unravelling the role of proteases in cancer. Clin Chim Acta 291: 113-135, 2000.

15. Jedeszko C and Sloan BF: Cathepsins in human cancer. Biol Chem 385: 1017-1027, 2004.

16. Bursch W: The autophagosomal-lysosomal compartment in programmed cell death. Cell Death Differ 8: 569-581, 2001.

17. Brunk UT, Dalen H, Roberg K and Hellquist HB: Photo-oxidative disruption of lysosomal membranes causes apoptosis of cultured human fibroblasts. Free Radic Biol Med 23: 616-626, 1997.

18. Seiler N and Raul F: Polyamines and apoptosis. J Cell Mol Med 9: 623-642, 2005

19. Dai H, Kramer DL, Yanag C, Murti KG, Porter CW and Cleveland JL: The polyamine oxidase inhibitor MDL 72527 selectively induces apoptosis of transformed haematopoietic cells through lysosomotropic effects. Cancer Res 59: 4844-4954, 1999.

20. de Duve $C$ and Wattiaux R: Functions of lysosomes. Annu Rev Physiol 28: 435-492, 1966.

21. de Duve C: The lysosome turns fifty. Nat Cell Biol 7: 847-849, 2005.

22. Codogno P and Meijer AJ: Autophagy and signalling: their role in cell survival and cell death. Cell Death Differ 12: 1509-1518, 2005.

23. Davies P and Allison AC: The secretion of lysosomal enzymes. Front Biol 45: 61-98, 1976.

24. Schwartz AL and Ciechanover A: The ubiquitin-proteasome pathway and pathogenesis of human diseases. Annu Rev Med 50: 57-74, 1999 .

25. Cuervo AM: Autophagy: Many paths to the same end. Mol Cell Biochem 263: 55-72, 2004.

26. Kos J and Lah TT: Cysteine proteinases and their endogenous inhibitors: target proteins for prognosis, diagnosis and therapy in cancer (review). Oncol Rep 5: 1349-1361, 1998.

27. Turk B, Turk D and Turk V: Lysosomal cysteine proteases: more than scavengers. Biochim Biophys Acta 1477: 89-111, 2000.

28. Majeski AE and Dice JF: Mechanisms of chaperone-mediated autophagy. Int J Biochem Cell Biol 36: 2435-2444, 2004.

29. Boya P, Gonzales-Polo RA, Casares N, Perfettini J, Dessen P, Larochette N, Metivier D, Maley D, Souquere S, Yoshimori T, Pierron G, Codogno P and Kroemer G: Inhibition of macro autophagy triggers apoptosis. Mol Cell Biol 25: 1025-1040, 2005.

30. Ogier-Denis and Codogno: Autophagy: a barrier or an adaptive response to cancer. Biochim Biophys Acta 1603: 113-128, 2003.

31. Gozuacik D and Kimchi A: Autophagy as a cell death and tumor suppressor mechanism. Oncogene 23: 2891-2906, 2004.

32. Yu Z, Persson HL, Eaton JW and Brunk UT: Intralysosomal iron, a major determinant of oxidant-induced cell death. Free Radic Biol Med 34: 1243-1252, 2003. 
33. Starke PE, Gilberton JD and Farber JL: Lysosomal origin of the iron required for cell killing by hydrogen peroxide. Biochem Biophys Res Commun 133(2): 371-379, 1985.

34. Brunk UT and Svensson I: Oxidative stress, growth factor starvation and Fas activation may all cause apoptosis through lysosomal leak. Redox Rep 4: 3-11, 1999.

35. Zdolsek J, Zhang H, Roberg K and Brunk UT: $\mathrm{H}_{2} \mathrm{O}_{2}$-mediated damage to lysosomal membranes of J-774 cells. Free Radic Res Commun 18: 71-85, 1993

36. Zhao M, Antunes F, Eaton JW and Brunk UT: Lysosomal enzymes promote mitochondrial oxidant production, cytochrome $\mathrm{c}$ release and apoptosis. Eur J Biochem 270: 3778-3786, 2003.

37. Yu Z, Li W, Hillman J and Brunk UT: Human neuroblastoma (SH-SY5Y) is highly sensitive to the lysosomotropic aldehyde 3-aminopropanal. Brain Res 1016: 163-169, 2004.

38. Foghsgaard L, Wissing D, Mauch D, Lademann U, Bastholm L, Boes M, Elling F, Leist M and Jäättelä M: Cathepsin B acts as a dominant execution protease in tumor cell apoptosis induced by tumor necrosis factor. J Cell Biol 153: 999-1010, 2001.

39. Deiss LP, Galinka H, Berissi H, Cohen O and Kimchi A: Cathepsin $\mathrm{D}$ protease mediates programmed cell death induced by interferon- $\gamma$, Fas/Apo-1 and TNF- $\alpha$. EMBO J 15: 3861-3870, 1996.

40. Kågedal K, Johansson U and Ollinger K: The lysosomal protease cathepsin $\mathrm{D}$ mediates apoptosis induced by oxidative stress. FASEB J 15: 1592-1594, 2001.

41. Bidere N, Lorenzo HK, Carmona S, Ladorge M, Harper F, Dumont $C$ and Senik A: Cathepsin D triggers Bax activation, resulting in selective apoptosis-inducing factor (AIF) relocation in $\mathrm{T}$ lymphocytes entering the early commitment phase to apoptosis. J Biol Chem 278: 31401-31411, 2003.

42. Erdal H, Berndtsson M, Castro J, Brunk U, Shoshan MC and Linder S: Induction of lysosomal membrane permeabilization by compounds that activate p53-independent apoptosis. Proc Natl Acad Sci USA 102: 192-197, 2005.

43. Zang Y, Beard RL, Chandraratna RA and Kanag JX: Evidence for a lysosomal pathway for apoptosis induced by the synthetic retinoid CD437 in human leukaemia HL-60 cells. Cell Death Differ 8: 477-485, 2001.

44. Szatrowsky TP and Nathan CE: Production of large amounts of hydrogen peroxide by human tumor cells. Cancer Res 51: 794-798, 1991.

45. Boya P, Gonzales-Polo RA, Poncet D, Andreau K, Vieira HL, Roumier T, Perfettini JL and Kroemer G: Mitochondrial membrane permeabilization is a critical step of lysosomeinitiated apoptosis induced by hydroxychloroquine. Oncogene 22: 3927-3936, 2003

46. Boya P, Andreau K, Poncet T, Zamzami N, Perfettini J, Metivier D, Ojcius DM, Jäättelä M and Kroemer G: Lysosomal membrane permeabilisation induces cell death in a mitochondrion-dependent fashion. J Exp Med 197: 1323-1334, 2003.

47. Kågedal K, Johansson AC, Johansson U, Heimlich G, Roberg K, Wang NS, Jürgensmeier JM and Ollinger K: Lysosomal membrane permeabilization during apoptosis-involvement of Bax? Int J Exp Pathol 86: 308-321, 2005.

48. Fischer J, Lullmann H and Lullman-Rauch R: Drug-induced lysosomal storage of sulphated glycosaminoglycans. Gen Pharmacol 27: 1317-1324, 1996.

49. Shau H and Dawson JR: Regulation of human natural killing by lysosomotropic and thiol-reactive agents. Immunology 55: 647-654, 1985.

50. Ziegler HK and Unanue ER: Decrease in macrophage antigen metabolism caused by ammonia and chloroquine is associated with inhibition of antigen presentation to T cells. Proc Natl Acad Sci USA 79: 175-178, 1982.

51. Steinberg TH: Cellular transport of drugs. Clin Infect Dis 19: 916-921, 1994.

52. Miller DK, Griffiths E, Lenard J and Firestone RA: Cell killing by lysosomotropic detergents. J Cell Biol 97: 1841-1851, 1983.

53. Drose S and Altendorf K: Bafilomycins and concanamycins as inhibitors of V-ATPases. J Exp Biol 200: 1-8, 1997.

54. Azuma $\mathrm{M}$ and Ohta $\mathrm{Y}$ : Changes in $\mathrm{H}^{+}$-translocating vacuolartype ATPase in the anterior silk gland cell of Bombyx mori during metamorphosis. J Exp Biol 201: 479-486, 1998.

55. Nakashima S, Hiraku Y, Tada-Oikawa S, Hishita T, Gabazza EC, Tamaki S, Imoto I, Adachi Y and Kawanishi S: Vacuolar $\mathrm{H}^{+}$ATPase inhibitor induces apoptosis via lysosomal dysfunction in the human gastric cancer cell line MKN-1. J Biochem 134: 359-364, 2003 .
56. Tanigaki K, Sasaki S and Ohkuma S: In bafilomycin A1resistant cells, bafilomycin $\mathrm{A} 1$ raised lysosomal $\mathrm{pH}$ and both prodigiosins and concanamycin A inhibited growth through apoptosis. FEBS Lett 537: 79-84, 2003.

57. Yoshikawa T, Kokura S, Tanaka K, Naito T and Kondo M: A novel cancer therapy based on oxygen radicals. Cancer Res 55: 1617-1620, 1995.

58. Agostinelli E, Arancia G, Dalla Vedova L, Belli F, Marra M, Salvi $\mathrm{M}$ and Toninello A: The biological functions of polyamine oxidation products by amine oxidases. Perspectives of clinical applications. Amino Acids 27: 347-358, 2004.

59. Park J, Choi K, Jeong E, Kwon D, Benveniste EN and Choi C: Reactive oxygen species mediate chloroquine-induced expression of chemokines by human astroglial cells. Glia 47: 9-20, 2004.

60. Yuan XM, Li W, Dalen H, Lotem J, Kama R, Sachs L and Brunk UT: Lysosomal destabilization in p53-induced apoptosis. Proc Natl Acad Sci USA 99: 6286-6294, 2002.

61. Ivanova S, Botchkina GL, Al-Abed Y, Meistrell M III, Batliwalla F, Dubinsky JM, Iadecola C, Wang H, Gregerssen PK, Eaton JW and Tracey KJ: Cerebral ischemia enhances polyamine oxidation: Identification of enzymatically formed 3-aminopropanal as an endogenous mediator of neuronal and glial cell death. $\mathrm{J}$ Exp Med 188: 327-340, 1998.

62. Wang Y, Devereux W, Woster PM, Stewart TM, Hacker A and Casero RA Jr: Cloning and characterization of a human polyamine oxidase that is inducible by polyamine analogue exposure. Cancer Res 64: 5370-5373, 2001.

63. Zeilhofer HU, Mollenhauer J and Brune K: Selective growth inhibition of ductal pancreatic adenocarcinoma cells by the lysosomotropic agent chloroquine. Cancer Lett 44: 61-66, 1989.

64. Seiler N, Chaabi M, Roussi S, Gosse F, Lobstein A and Raul F: Synergism between apple procyanidins and lysosomotropic drugs: potential in chemoprevention. Anticancer Res 26: 3381-3385, 2006.

65. Zamora JM and Beck WT: Chloroquine enhancement of anticancer drug cytotoxicity in drug-resistant human leukaemia cells. Biochem Pharmacol 35(23): 4303-4310, 1986.

66. Shiraishi N, Akiyama S, Kobayashi M and Kuwano M: Lysosomotropic agents reverse multidrug resistance in human cancer cells. Cancer Lett 30: 251-259, 1986.

67. Seiler N, Duranton B and Raul F: The polyamine oxidase inactivator MDL 72527. Prog Drug Res 59: 1-40, 2002.

68. Brunton VG, Grant MH and Wallace HM: Mechanism of spermine toxicity in baby hamster kidney (BHK) cells. Biochem J 280: 193-198, 1991.

69. Seiler N, Duranton B, Gossé F and Raul F: Spermine cytotoxicity to human colon carcinoma-derived cells $(\mathrm{CaCo}-2)$. Cell Biol Toxicol 16: 117-130, 2000

70. Seiler N, Duranton B, Vincent F, Gossé F, Renault J and Raul F: Inhibition of polyamine oxidase enhances the cytotoxicity of polyamine oxidase substrates: A model study with $\mathrm{N}^{1}-(\mathrm{n}-$ octanesulfonyl)spermine and human colon cancer cells. Int J Biochem Cell Biol 32: 703-716, 2000.

71. Seiler N, Badolo L, Duranton B, Vincent F, Schneider Y, Gossé F and Raul F: Effect of the polyamine oxidase inactivator MDL 72527 on $\mathrm{N}^{1}$-(n-octanesulfonyl)spermine toxicity. Int J Biochem Cell Biol 32: 1055-1068, 2000

72. Seiler N, Renault J, Gossé F, Roussi S and Raul F: Cytotoxicity of the polyamine oxidase inactivator MDL 72527 to cancer cells: comparison with a saturated structural analogue. Int J Oncol 27: 1669-1676, 2005.

73. Duranton B, Holl V, Schneider Y, Carnesecchi S, Gosse F, Raul F and Seiler N: Cytotoxic effects of the polyamine oxidase inactivator MDL 72527 on two human colon carcinoma cell lines SW 440 and SW 620. Cell Biol Toxicol 18: 381-396, 2002.

74. Agostinelli E, Dalla Vedova L, Belli F, Condello M, Arancia G and Seiler N: Sensitization of human colon adenocarcinoma cells (LoVo) to reactive oxygen species by a lysosomotropic compound. Int J Oncol 29: 947-955, 2006.

75. Agostinelli E, Belli F, Molinari A, Condello M, Palmigiani P, Marra M, Seiler N and Arancia G: Toxicity of enzymatic oxidation products of spermine to human melanoma cells (M14): sensitisation by heat and MDL 72527. Biochim Biophys Acta 1763: 1040-1050, 2006

76. Loo TW and Clarke DM: Recent progress in understanding the mechanism of P-glycoprotein-mediated drug efflux. J Membr Biol 206: 173-185, 2005 . 
77. Gottesman MM and Pastan I: Biochemistry of multidrug resistance mediated by the multidrug transporter. Annu Rev Biochem 62: 385-427, 1993.

78. Breier A, Barancik M, Sulova Z and Uhrik B: P-glycoprotein: implications of metabolism of neoplastic cells and cancer therapy. Curr Cancer Drug Targets 5: 457-468, 2005.

79. Szabo D, Keyzer H, Kaiser HE and Molnar J: Reversal of multidrug resistance of tumor cells. Anticancer Res 20: 4261-4274, 2000 .

80. Wadkins RM and Roepe PD: Biophysical aspects of Pglycoprotein-mediated multidrug resistance. Int Rev Cytol 171: 121-165, 1997.

81. Zamora JM, Pearce HL and Beck WT: Physical chemical properties shared by compounds that modulate multidrugresistance in human leukaemic cells. Mol Pharmacol 33: 454-462, 1988.

82. Skovsgaard T, Dano K and Nissen NI: Chemosensitizers counteracting acquired resistance to anthracyclines and Vinca alkaloids in vivo. A new treatment principle. Cancer Treat Rev 11 (Suppl A9): 63-72, 1984.

83. Thimmaiah KN, Jayashree BS, Germain GS, Houghton PJ and Horon JK: Characterization of 2-chloro- $\mathrm{N}^{10}$-substituted phenoxazines for reversing multidrug resistance in cancer cells. Oncol Res 10: 29-41, 1998.

84. Choi SU, Park SH, Kim KH, Choi EJ, Kim S, Park WK, Zhang YH, Kim HS, Jung NP and Lee CO: The bisbenzylisoquinoline alkaloids, tetrandine and fangchinoline, enhance the cytotoxicity of multidrug resistance-related drugs via modulation of P-glycoprotein. Anticancer Drugs 9: 255-261, 1998.

85. Rothenborg-Jensen L, Hansen HF, Wessel I, Nitiss JL, Schmidt G, Jensen PB, Sehested M and Jensen LH: Linker length in podophyllotoxin-acridine conjugates determines potency in vivo and in vitro as well as specificity against MDR cell lines. Anticancer Drug Des 16: 305-315, 2001.

86. Vezmar M and Georges E: Direct binding of chloroquine to the multidrug resistance protein (MRP): possible role for MRP in chloroquine drug transport and resistance in tumor cells. Biochem Pharmacol 56: 733-742, 1998.

87. Akiyama S, Gottesman MM, Hanover JA, Fitzgerald DJP, Willingham MC and Pastan I: Verapamil enhances the toxicity of conjugates of epidermal growth factor with Pseudomonas exotoxin and antitransferrin receptor with Pseudomonas exotoxin. J Cell Physiol 120: 271-279, 1984.

88. Akiyama S, Tomita K and Kuwano M: The effect of calcium antagonists on the proteolytic degradation of low density lipoprotein in HeLa cells. Exp Cell Res 158: 192-204, 1985.

89. Gosland MP, Gillespie MN, Tsuboi CP, Tofig S, Olson JW, Crooks PA and Aziz SM: Reversal of doxorubicin, etoposide, vinblastine and taxol resistance in multidrug resistant human sarcoma cells by a polymer of spermine. Cancer Chemother Pharmacol 37: 593-600, 1996.

90. Drori S, Eytan GD and Assaraf YG: Potentiation of anticancer drug cytotoxicity by multidrug-resistance chemosensitizers involves alterations in membrane fluidity leading to increased membrane permeability. Eur J Biochem 228: 1020-1029, 1995.

91. Dorr RT and Liddil ID: Modulation of Mitomycin C-induced multidrug resistance in vitro. Cancer Chemother Pharmacol 27: 290-294, 1991.

92. Klohs WD and Steinkampf RW: The effect of lysosomotropic agents and secretory inhibitors on anthracycline retention and activity of multiple drug-resistant cells. Mol Pharmacol 34: 180-185, 1988

93. Dudeja PK, Anderson KM, Harris JS, Buckingham L and Coon JS: Reversal of multidrug resistant phenotype: relationship to membrane lipid fluidity. Arch Biochem Biophys 319: 309-315, 1995.

94. Averill-Bates DA, Cherif A, Agostinelli E, Tanel A and Fortier G: Antitumoral effect of native and immobilized bovine serum amine oxidase in a mouse melanoma model. Biochem Pharmacol 69: 1693-1700, 2005.

95. Lee YJ and Shacter E: Hydrogen peroxide inhibits activation, not activity, of cellular caspase-3 in vivo. Free Radic Biol Med 29: 684-692, 2000.
96. Teramoto S, Tomita T, Matsui H, Ohga E, Matsuse T and Ouchi Y: Hydrogen peroxide-induced apoptosis and necrosis in human lung fibroblasts: protective roles of glutathione. Jpn J Pharmacol 79: 33-40, 1999.

97. Kern JC and Kehrer JP: Acrolein-induced cell death: a caspaseinfluenced decision between apoptosis and oncosis/necrosis. Chem Biol Interact 139: 79-95, 2002.

98. Calcabrini A, Arancia G, Marra M, Crateri P, Befani O, Martone A and Agostinelli E: Enzymatic oxidation product of spermine induce greater cytotoxic effects on human multidrugresistant colon carcinoma cells (LoVo) than on their wild type counterparts. Int J Cancer 99: 43-52, 2002.

99. Agostinelli E, Arancia G, Calcabrini A, Matarrese P, Mondovì B and Pietrangeli P: Hyperthermia-induced biochemical and ultrastructural modifications in cultured cells. Exp Oncol 17: 269-276, 1995.

100. Agostinelli E, Belli F, Dalla Vedova L, Marra M, Crateri P and Arancia G: Hyperthermia enhances cytotoxicity of amine oxidase and spermine on drug-resistant colon adenocarcinoma cells (LoVo). Int J Oncol 28: 1543-1553, 2006.

101.Demers N, Agostinelli E, Averill-Bates DA and Fortier G: Immobilization of native and poly(ethylene glycol)-treated ('PEGylated') bovine serum amine oxidase into a biocompatible hydrogel. Biotechnol Appl Biochem 33: 201-207, 2001.

102. Heby O and Persson L: Molecular genetics of polyamine synthesis in eukaryotic cells. Trends Biochem Sci 15: 153-158, 1990.

103. Fehrenbacher N, Gyrd-Hansen M, Poulsen B, Felbor U, Kallunki T, Boes M, Weber E, Leist $M$ and Jäättelä $M$ : Sensitization to the lysosomal cell death pathway upon immortalization and transformation. Cancer Res 64: 5301-5310, 2004.

104. Urano M, Kuroda M and Nishimura Y: For the clinical application of thermochemotherapy given at mild temperatures. Int J Hyperthermia 15: 79-107, 1999.

105. Ginsburg H: Should chloroquine be laid to rest? Acta Trop 96 16-23, 2005.

106. Savarino A, Di Trani L, Donatelli I, Cauda R and Cassone A: New insights into the antiviral effects of chloroquine. Lancet Infect Dis 6: 67-69, 2006.

107. Briceno E, Reyes S and Sotelo J: Therapy of glioblastoma multiforme improved by the antimutagenic chloroquine. Neurosurg Focus 14: e3, 2003.

108. Porter CW, Stanek J, Black J, Vaughan M, Ganis B and Pleshkewych A: Morphological evidence for an apparent lysosomotropic activity by unsaturated putrescine analogues. Cancer Res 50: 1929-1935, 1990.

109. Rosenfeld CS: Antileukemic activity of phenylalanine methyl ester (PME): a lysosomotropic peptide methyl ester. Stem Cells 12: 198-204, 1994.

110. Jadot M, Bielande V, Beauloye V, Wattiaux-de Conick S and Wattiaux R: Cytotoxicity and effect of glycyl-D-phenylalanine2-naphthylamide on lysosomes. Biochim Biophys Acta 1027: 205-209, 1990.

111. Uchimoto T, Nohara H, Kamehara R, Iwamura M, Watanabe N and Kobayashi T: Mechanism of apoptosis induced by lysosomotropic agent L-leucyl-L-leucine methyl ester. Apoptosis 4: 357-362, 1999

112. Mizuta H, Watanabe S, Sakurai Y, Nishiyama K, Furuta T, Kobayashi Y and Iwamura M: Design, synthesis, photochemical properties and cytotoxic activities of water-soluble caged Lleucyl-L-leucine methyl esters that control apoptosis of immune cells. Bioorg Med Chem 10: 675-683, 2002.

113.Lullmann-Rauch R, Pods R and Von Witzendorff B: Tiloroneinduced lysosomal storage of sulphated glycosaminoglycans can be separated from tilorone-induced enhancement of lysosomal enzyme secretion. Biochem Pharmacol 49: 1223-1233, 1995.

114. Li W, Yuan XM, Ivanova S, Tracey KJ, Eaton JW and Brunk UT: 3-Aminopropanal, formed during cerebral ischaemia, is a potent lysosomotropic neurotoxin. Biochem J 371: 429-436, 2003. 